\title{
Morphological Characterization and Physical Dormancy of Bauhinia winitii Seed: Living Collection of Purwodadi Botanic Garden
}

\author{
Dewi Ayu Lestari, Elok Rifqi Firdiana \\ Purwodadi Botanic Garden - Research Center for Plant Conservation and Botanic Garden, \\ Indonesian Institute of Sciences (LIPI), Indonesia \\ *Corresponding Author: chunyang_dee@yahoo.co.id; elok.firdiana@gmail.com
}

Submitted: 2021-06-03. Revised: 2021-07-31. Accepted: 2021-08-16

\begin{abstract}
Bauhinia winitii Craib (Fabaceae, Caesalpinioideae) is a woody climber which is currently included in endangered species list. $B$. winitii seeds are orthodox seeds in which it has hard coat morphologically. Therefore, $B$. winitii seeds often undergo physical dormancy which can be broken through immersion in certain liquid media. This study aimed to characterize the morphology of $B$. winitii seeds and determine the pre-sowing treatment method to accelerate the seeds germination of $B$. winitii. External morphological characterization was carried out by observing the seeds quantitative and qualitative parameters. Characterization of seeds internal morphology was conducted using a digital microscope. Physical dormancy breaking was carried out by immersion in warm and cold water for 24 hours. Morphological characterization data were analyzed descriptively, while seed germination data were analyzed quantitatively by using one-way ANOVA followed by LSD test (with confidence level of 95\%). B. winitii has pod-shaped fruits with 26 seeds per pod, the seeds are $1.36 \mathrm{~cm} \mathrm{x} 1 \mathrm{~cm}$ in size, $0.47 \mathrm{~cm}$ thick and weighed $0.5 \mathrm{~g}$, oblong to conical in shape, smooth and shine surface, with light to dark brown in color. Seeds immersion treatment in warm water could break the physical dormancy of $B$. winitii seeds thus $63 \%$ of the seeds were able to germinate and it was significantly different compared to control and cold water immersion treatment. Technical to germinate $B$. winitii seed can be known from pre-sowing treatment. This study can be used as a reference for seed identification and germination technical of $B$. winitii seed.
\end{abstract}

Key words: Bauhinia winitii; morphology; orthodox seed; physical dormancy

How to Cite: Lestari, D. A., \& Firdiana, E. R. (2021). Morphological Characterization and Physical Dormancy of Bauhinia winitii Seed: Living Collection of Purwodadi Botanic Garden. Biosaintifika: Journal of Biology \& Biology Education, 13(2), $195-200$.

DOI: http://dx.doi.org/10.15294/biosaintifika.v13i2.30501

\section{INTRODUCTION}

Bauhinia winitii Craib is a woody climber of the Fabaceae family, subfamily Caesalpinioideae and synonym of Lysiphyllum winitii (Craib) de Witt. It is distributed in the tropics and is an endemic plant from Thailand (Sraphet et al., 2021). Based on an assessment conducted by the Botanic Gardens Conservation International database for threatened tree species, $B$. winitii is classified as an endangered species (Rivers et al., 2015) which is given to taxons facing a high risk of extinction (Dublin, 2019).

$B$. winitii seeds exhibited orthodox seed storage characteristics that are resistant to long term storage just like other typical legume seeds (Waiboonya et al., 2019; Solberg et al., 2020) in seed bank. This characterisistic is needed for seed conservation (Zuhri et al., 2019). It is because morphologically orthodox seeds generally have a hard seed coat. The morphological structure of seeds can be identified through characterization, where studies concerning it are very important both for identification process and for diversity determination of a species. Morphometric analysis is one form of morphological characterization which is closely related to the adaptation process of a species to the environment (Lestari et al., 2018; Magalhaes et al., 2021).
Seeds might undergo dormancy when the environmental conditions are not suitable for germination. However, even in good environmental conditions (sufficient humidity, suitable temperature and light), viable seeds could fail to germinate (Schmidt, 2002). The probable causes of such seed dormancy are hard seed coats, immature embryo growth, and seeds containing inhibitory substances in the fruit or seeds that prevent germination, as well as a combination of several types of dormancy factors (Zanzibar, 2017). Dormancy in B. winitii seeds is a physical type caused by structural restrictions on seed germination. As a result of the hardness of the seed coat, the seeds have a mechanical barrier against the entry of water or gas into the seed during the imbibition process. This physical dormancy can be broken by immersion in certain liquid media, such as water or certain chemical solutions. The immersion serves as an alternative pre-sowing treatment to speed up the imbibition process so that the seeds germinate quickly. Previous study carried out by Ekasari (2011) showed that immersion in warm water could break the seed dormancy of Calliandra tetragona, also the member of Fabaceae, indicated by $96 \%$ seed germination compared to control $(35 \%$ seed germination). Breaking the dormancy for hard seed coats can be carried out by immersion in cold or 
warm water and treatment with strong acids (Abbas, 2013; Rusdy, 2017).

The studies of seed morphology underlie processes in biological and ecological sciences, such as germination, seed dispersal, and dormancy (Diantina et al., 2020). Such morphological studies, both internal and external, are very important to differentiate taxonomic groups through seed germination and viability tests for seed conservation efforts (Rios et al., 2016). Morphological characters of fruit and seeds are very important in understanding plant taxonomy and systematics, especially as an introduction to seed plants (Lestari \& Asih, 2015).

The purpose of this study was to determine the internal and external morphological structure of $B$. winitii seeds and to determine the appropriate presowing treatment method to accelerate the seeds germination of $B$. winitii. The results of this study are expected to be used as a reference for the identification process of seeds and seed germination of B. winitii.

\section{METHODS}

\section{Time and place of study}

This study was conducted in March 2020 - April 2021 in the in-vitro culture laboratory and nursery greenhouse of the Purwodadi Botanic Garden (PBG), Pasuruan, East Java. The Bauhinia winitii seed materials used were obtained from living collections conserved ex-situ in block II.E.3 of PBG.

\section{Morphological characterization of $\boldsymbol{B}$. winitii seeds}

The dried pods of $B$. winitii were harvested, then peeled to collect the seeds. In every pod, there were $2-5$ seeds. The seeds were then dried until ready to use. For external morphological characterization of $B$. winitii seeds, a sample of 100 seeds was used and the length, width, thickness, and weight of seeds were measured (for quantitative characters), as well as the color, surface, and shape (for qualitative characters). Length and width of seeds were measured using millimeter paper, with the length of the seeds was measured from the base to the tip, while the width of the seeds was measured at the widest part of the seeds or the seed diameter (Das Neves et al., 2018). Seed thickness was determined using digital calipers and seed weight was measured using digital balance. Detailed observations on the external morphological characterization of seeds referred to Sangalli et al. (2012) and Lestari (2013). The detailed crosssectional morphology of $B$. winitii seeds was observed using Dino-Lite digital microscope Premier (AM3111/3113 Series).
Breaking the physical dormancy of $B$. winitii seeds

This study of physical dormancy of $B$. winitii seeds used a completely randomized design. The control was fresh and untreated seeds, while the treatments were the immersion of seeds in warm water and in cold water each for 24 hours. The number of seeds for control and each treatment was 25 with three replications. All seeds were then sown in a sandbox and watered when the planting medium looked dry. The parameters observed were the number of seeds germinated, the seed germination speed, the pattern and type of germination. The number of seeds germinated was used to determine the germination percentage and rate which referred to Sutopo (2010), Davies et al. (2015) and Latifah et al. (2020), with the following formula:

$$
\begin{aligned}
& \text { Percentageof germination }=\frac{\text { number of seed germinated }}{\text { number of seed sown }} \times 100 \% \\
& \text { germination rate }=\frac{\sum \mathrm{n}}{\sum(\mathrm{txn})} \times 10 \mathrm{C}
\end{aligned}
$$

Note: $\mathrm{n}=$ number of germinated seeds and $\mathrm{t}=$ seed germination speed (days)

\section{Data analysis}

Data on the external morphological characterization and cross-section (internal) of $B$. winitii seeds were analyzed descriptively. The seed germination data were analyzed statistically using one-way ANOVA with the aid of Microsoft Excel. If there was a significant difference, it was continued with the LSD (Least Significant Difference) test with a confidence level of $95 \%$.

\section{RESULTS AND DISCUSSION}

\section{Morphological characterization of Bauhinia winitii seed}

B. winitii has pod-shaped fruit with 2-6 seeds per pod, the fruit skin is dark brown to blackish brown, and its surface is coarse and hairy with size ranging from 17-25 cm x 4.5-5 cm (Figure 1a). Fruits of Fabaceae are generally pod-shaped, some are winged, such as Flemingia macrophylla, Koompassia excelsa, Myroxylon balsamum and Pterocarpus indicus (Gumilang et al., 2018). The pod characteristics are positively correlated with the characteristics of the seeds (Ningsih et al., 2019). One example is Bauhinia scandens which has brown pod, with a length of 1.8-3 $\mathrm{cm}$ and a width of 1-1.6 cm (Kuswanto, 2016). Each pod contains 1 or 2 elliptical to obovoid seeds with a length of $8 \mathrm{~mm}$ (Kuswanto, 2016).

The seeds of $B$. winitii are $1.36 \mathrm{~cm} \times 1 \mathrm{~cm}$ in size, $0.47 \mathrm{~cm}$ thick and weighed 0.5 gram, oblong to conical in shape, smooth surface, shine with light to 
dark brown in color (Figure 1b). Based on the crosssection of the seeds (Figure 2), sorted from the outermost to the innermost, the internal parts of $B$. winitii seeds consist of testa and tegmen (seed coat), endosperm, and microfiles. Radicle is composed of the funiculus and hilum. The radicle will become a new individual through the emergence of hypocotyl and epicotyl during germination. The morphological structure of the seed radicle of the subfamily Caesalpinioideae consists of a hilum in the middle of which there is a hilar groove with a micropyle at the tip of the radicle and lens at the base of the radicle. The hilum functions as a hygroscopic valve that is responsive to the growing environment (LPWG, 2017). Furthermore, it is also a part of the seed that is able to adapt to environmental conditions so that it is resistant to dry tropics.

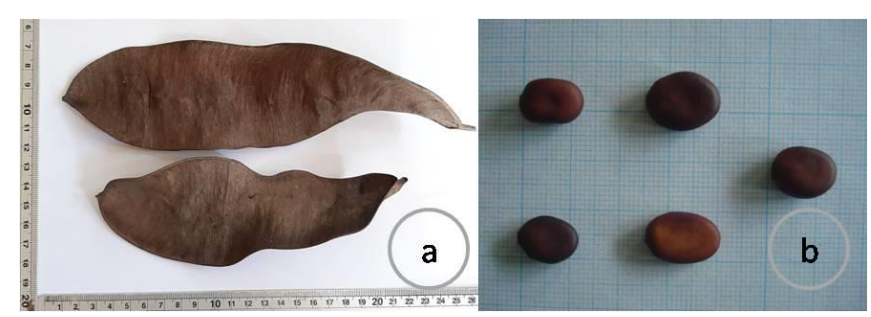

Figure 1. Morphology of fruit and seed of Bauhinia winitii; (a.) Fruit and (b.) Seed

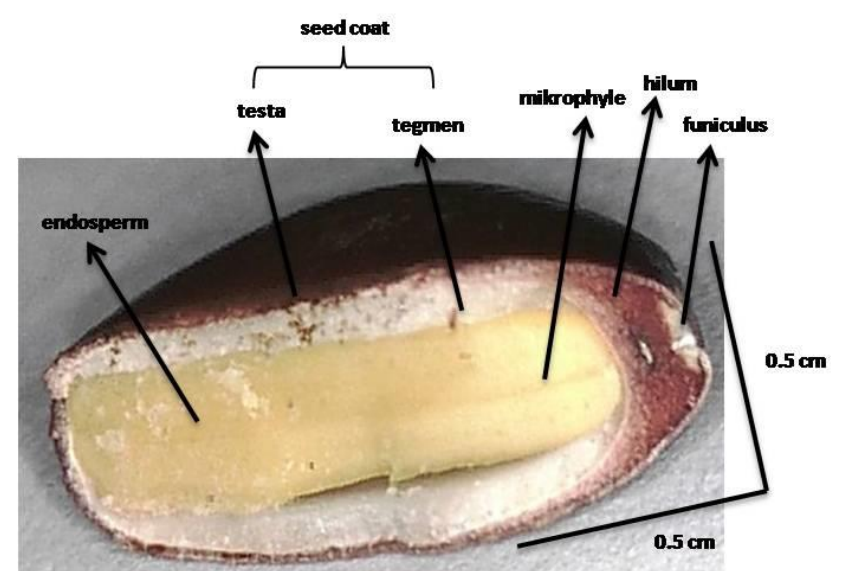

Figure 2. Cross-section of Bauhinia winitii seed

Analysis of plants morphological characterization in general contributes to the purposes of identification, characterization, and genetic diversity. Ajisyahputra et al. (2017) and Magalhaes et al. (2021) stated that morphobiometric analysis is useful to characterize or even identify certain species. The variation in seed morphology is tremendous and these characters are relatable to the way the seeds germinate and spread. Thus, it is a form of ecological adaptation (Zhang et al., 2015; Hariyanto, 2019).

\section{Physical dormancy of Bauhinia winitii seed}

Several species of the Fabaceae, especially living in the tropics, have seeds with a physical dormancy that are strongly influenced by the environment. One of them is seeds of the genus Bauhinia which have a low germination rate in nature. Based on Figure 3, breaking the the physical dormancy of $B$. winitii seeds could be performed through immersion in warm water for 24 hours. It triggered seed germination hence the germination percentage reached $63 \%$. This germination percentage is categorized as moderate since it ranges from $51-80 \%$, while the germination of control (fresh seeds) and seeds immersed in cold water for 24 hours is categorized as low (range of 1-50\%). The germination rate of control and both treatments increased on the $5^{\text {th }}$ day after sowing and decreased significantly until the end of the observation. Thus, the breaking of physical dormancy through water immersion did not affect the germination rate of $B$. winitii seeds. Analysis of variance showed that immersion of $B$. winitii seeds in warm water for 24 hours gave a significant difference compared to other treatments. There was no significant difference in germination between controls and seeds immersed in cold water. Physical dormancy did not affect significantly the seed germination speed (Table 1) although fresh seeds seemed to germinate longer than seeds with water immersion treatment. It is due to the pre-treatment before sown hence the imbibition process already occurred during the treatment.

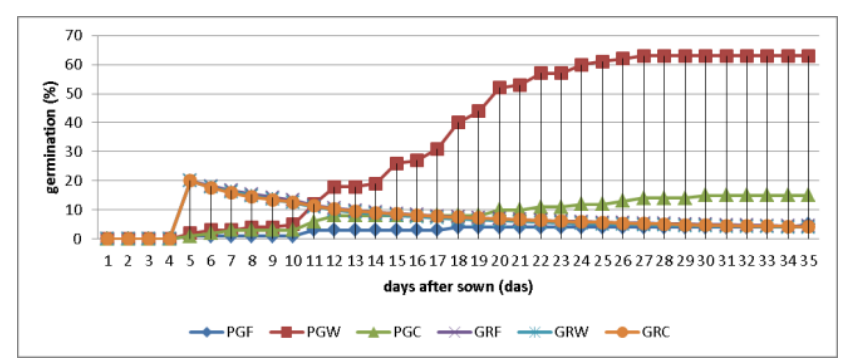

Figure 3. Seed germination of Bauhinia winitii; PGF $=$ germination percentage of fresh seeds (control), PGW = germination percentage of seeds immersed in warm water for 24 hours, PGC = germination percentage of seeds immersed in cold water for 24 hours, GRF = germination rate of fresh seeds (control), GRW = germination rate of seeds immersed in warm water for 24 hours, and GRC = germination rate of seeds immersed in cold water for 24 hours 
Table 1. Statistic of seed germination of B. winitii

\begin{tabular}{lcc}
\hline Treatment & $\begin{array}{c}\text { Germination } \\
(\%)\end{array}$ & $\begin{array}{c}\text { Germination } \\
\text { speed (das) }\end{array}$ \\
\hline $\begin{array}{l}\text { Control (fresh } \\
\text { seeds) }\end{array}$ & $5^{\mathrm{a}}$ & $11^{\mathrm{a}}$ \\
$\begin{array}{l}\text { Immersion in } \\
\text { warm water for }\end{array}$ & $63^{\mathrm{b}}$ & $7^{\mathrm{a}}$ \\
$\begin{array}{l}\text { 24 hours } \\
\text { Immersion in cold }\end{array}$ & $15^{\mathrm{a}}$ & $6^{\mathrm{a}}$ \\
$\begin{array}{l}\text { water for 24 } \\
\text { hours }\end{array}$ & & \\
\hline
\end{tabular}

Note: Different notations indicate that there are significant differences between treatments on the same parameter with a confidence level of $95 \%$

Physical dormancy of Bauhinia seeds can be broken as long as there is a process of imbibition by water hence the surface of the seeds becomes soft and the environmental conditions are supportive, considering that the seed coat is difficult to penetrate (Rieks et al., 2006; Tauro et al., 2009; Wen et al., 2009). Besides having physical dormancy, Bauhinia seeds are classified as seeds with orthodox storage characteristics. Those two are characteristics of most seeds of the legume (Jayasuriya et al., 2013).

The type of seed germination of $B$. winitii was epigeal shown by the lifting of the hypocotyl to the soil surface (Figure 4a) with a simultaneous germination pattern for the seeds immersed in warm water for 24 hours (Figure 4b). Meanwhile, the seeds immersed in cold water and control (fresh seeds) had a gradual germination pattern.



Figure 4. Type and pattern of seed germination of Bauhinia winitii; (a.) Epigeal germination type and (b.) Simultaneous germination pattern in seeds immersed in warm water

Immersion in warm water is effective in increasing seed germination, especially for genus Bauhinia. This was also proven for small $(1-5 \mathrm{~mm})$ and large $(5-10 \mathrm{~mm})$ seeds of B. thonningii by $40 \%$ and $53.3 \%$ of germination respectively (Mwase \& Mvula, 2011). B. rufescens seeds treated with scarification (wounding) gave the best results on the 94.7\% percentage of germination compared to seeds treated with water immersion and control (Agustin \& Wawaningrum, 2015), while Opoku et al (2018) stated that immersion of $B$. rufescens seeds in hot water at $65^{\circ} \mathrm{C}$ for 60 minutes and/or immersed in $\mathrm{H}_{2} \mathrm{SO}_{4}$ for 45 minutes and then immersed in water for 24 hours could be pre-treatment before sowing in order to increase germination rate and strong vegetative growth. Seeds immersion in $\mathrm{H}_{2} \mathrm{SO}_{4}$ for 30 minutes increases the germination percentage and reduces the germination period. This treatment also applied to B. divaricata and B. malabarica seeds (Alderete-Chavez et al., 2011; Pillai et al., 2019). B. purpurea seeds immersed in hot water for 2-5 minutes then immersed in cold water overnight resulted in a germination percentage of 59\% and significantly different compared to control (Hanumantha et al., 2014). On the other hand, seed dormancy of $B$. variegata could be broken by scarification or wounding of the seed coat (Martinelli-Seneme et al., 2006).

Seeds with orthodox categories (such as those belong to genus Bauhinia) are resistant to storage conditions thus they are able to defend themselves so that they remain viable in the long term. It is very important in seed conservation efforts. Nevertheless, they have physical dormancy that could be broken by pre-sowing treatment. As this case study on $B$. winitii which showed that pre-sowing treatment by the seeds immersion in warm water overnight was able to break its physical dormancy.

Thus this study provides new information about seed biology, especially on the morphological character of $B$. winitii seeds both externally and internally. In addition, this study also confirmed that immersion in warm water could break seed dormancy in the genus Bauhinia, and in particular in B. winitii. This can be a reference to break seed dormancy in other species that have similar characteristics, i.e. having a hard outer seed coat and having orthodox storage characteristics. The detail information about seed biology can be utilized for identification of seed plant, and pre-sowing treatment can be utilized for plant breeding especially to obtain the uniform seedling in large quantities.

\section{CONCLUSION}

Bauhinia winitii seeds are oblong to conical in shape, smooth and shine surface, with light to dark brown in color, $1.36 \mathrm{~cm} \mathrm{x} 1 \mathrm{~cm}$ in size, $0.47 \mathrm{~cm}$ thick,weighed $0.5 \mathrm{~g}$ and consist of testa and tegmen (seed coat), endosperm and microfils. It belongs to genus Bauhinia which has resistance to storage conditions and it is very important in seed conservation efforts. Nevertheless they have physical dormancy that could be broken by pre-sowing treatment. As this case study on $B$. winitii which showed that pre-sowing treatment by the seeds 
immersion in warm water overnight were able to break its physical dormancy.

\section{REFERENCES}

Agustin, E. K., \& Wawaningrum, H. (2015). Scarification technique of Bauhinia rufescens seed germination. In: Proceeding of Seminar Horticulture Indonesia, Bogor, 19-20 October 2015. Bogor: LPPM IPB Publishing. 501-505.

Ajisyahputra, N. R., Palupi, E. R., Armini, N. M., Mulyono, J., \& Krisantini. (2017). Evaluation of growth, flowering and seed morphology of bat flower, Tacca chantrieri Andre. Journal of Tropical Crop Science, 4(2), 64-69.

Alderete-Chavez, A., Cruz-Landero, N. D., GuerraSantos, J. J., Guevara, E., Gelabert, R., CruzMagana, L. R. D., Nunez-Lara, E., \& Brito, R. (2011). Promotion of germination of Bauhinia divaricata L. seeds by effects of chemical scarification. Research Journal of Seed Science, 4, 51-57.

Das Neves, M. I. R. S., Neto, J. C. A., Ferreira, V. M., da Silva, C. B., Junior, J. L. A. M., Melo, L. D. F. A., Farias, A. S., Galvao, E. R., \& da Silva, V. S. G. (2018). Morphometric characterization and seed dormancy overcoming of Sapindus saponaria L. Journal of Agricultural Science, 10(7), 329-341.

Davies, R., Di Sacco, A., \& Newton, R. (2015). Germination testing: procedures and evaluation. Technical information sheet_13a. Royal Botanic Gardens Kew, 1, 1-4.

Diantina, S., McGill, C., Millner, J., Nadarajan, J., Pritchard, H. W., \& McCormick, A. C. (2020). Comparative seed morphology of tropical and temperate orchid species with different growth habits. Plants, 9(2), 161.

Dublin, H. (2019). IUCN red list of threatened species. Encyclopedia Britannica. Retrieved from https://www.britannica.com/topic/IUCN-Red-Listof-Threatened-Species.

Ekasari, I. (2011). Affect of canopy stratum and methods of breaking seed dormancy on seedling growth of Calliandra tetragona Beth. and Acacia tamarindifolia (L.) Willd. Jurnal Biologi Indonesia, 7(2), 243-249.

Gumilang, A. R., Widjaja, A. H., Lestari, D. A., Latifah, D., etc. (2018). Anemochory Flora Green Earth. Jakarta: LIPI Press.

Hanumantha, M., Gunaga, R. P., Biradar, S. S., Patil, R. S., \& Shankar, P. (2014). Enhancement of seed germination in stored seeds using different presowing treatments in Bauhinia purpurea L. Journal of Applied and Natural Science, 6(2), 707-710.
Hariyanto, S. (2019). Variations in seed micromorphology and morphometry of native Indonesian Phalaenopsis and Paphiopedilum orchids. Biodiversitas, 20(12), 3559-3567.

Jayasuriya, K. M. G. G., Wijetunga, A. S. T. B., Baskin, J. M. , \& Baskin, C. C. (2013). Seed dormancy and storage behaviour in tropical Fabaceae: a study of 100 species from Sri Lanka. Seed Science Research, 23(4), 257-269.

Kuswanto, L. (2016). Morphological characteristics of a unique 'chain tree' Bauhinia scandens Willd (Caesalpinioideae, Leguminosae) from Pager Wunung Darupono Conservation Park, Central Java, Indonesia. Journal of Tropical Crop Science, 3(2), 56-60.

Latifah, D., Wardani, F. F., \& Zulkarnaen, R. N. (2020). Short comunication: seed germination, seedling survival and storage behavior of Koompassia excelsa (Leguminosae). Nusantara Bioscience, 12(1), 46-49.

Lestari, D. A. (2013). Characterization of external morphology on various seeds in Purwodadi Botanic Garden. In: Proceeding of International Conference The 4th Green Technology. Malang, 9 November 2013. Malang: Faculty of Science and Technology, Islamic State University of Maulana Malik Ibrahim. 159-164.

Lestari, D., \& Asih, N. P. S. (2015). Management of Eka Karya Bali Botanic Garden's seed bank. Prosiding Seminar Nasional Masyarakat Biodiversitas Indonesia, 1(3), 515-520.

Lestari, D. A., Aliviyanti, D., Mariantika, L., \& Kurniawan, N. (2018). Genetic diversity of Diospyros cauliflora Blume and Diospyros lolin Bakh. From Purwodadi Botanical Garden collection based on morphometric analysis. Plant and Animal Research Journal, 1(1), 13-19.

LPWG. (2017). A new subfamily classification of the Leguminosae based on a taxonomically comprehensive phylogeny. Taxon, 66(1), 44-77.

Magalhaes, P. S. C., Teixeira, M. C. S. A., Mendes, M. R. A., Lemos, J. R., \& Rodrigues, B. J. S. (2021). Fruit and seed morphometry and methods for overcoming sleep of Anadenanthera colubrina (Vell.) Brenan (Fabaceae). Research, Society and Development, 10(3), e6010313034.

Martinelli-Seneme, A., Possamai, E., Schuta, L. R., \& Vanzolini, S. (2006). Germination and sanity of seeds of Bauhinia variegata. Revista Arvore, 30(5), 719-724.

Mwase, W. F., \& Mvula, T. (2011). Effect of seed size and pre-treatment methods of Bauhinia thonningii Schum. on germination and seedling growth. African Journal of Biotechnology, 10(13), 5143-5148. 
Ningsih, F., Zubaidah, S., \& Kuswantoro, H. (2019). Diverse morphological characteristics of soybean (Glycine $\max$ L. Merill) pods and seeds germplasm. IOP Conference Series: Earth Environmental Science, 276, 012014.

Opoku, J. A., Amissah, J. N., Essilfie, M. E., \& Norman, J. C. (2018). Effect of pre-sowing treatments on seed germination and seedling growth of silver butterfly tree (Bauhinia rufescens). Current Agricultural Research, 6(3).

Pillai, P. K. C., Viswanath, S. C., Hrideek, T. K., \& Jiji, A. H. (2019). Seed Characteristics and Germination Behaviour of Bauhinia malabarica Roxb. Thailand: Horticultural Book.

Rieks, D., Klinken, V., Flack, L. K., \& Pettit, W. (2006). Wet-season dormancy release in seed banks of a tropical leguminous shrub is determined by wet heat. Annals of Botany, 98, 875-883.

Rios, P. A. F., Araujo, J. C., Ferreira, V. M., \& Das Neves, M. I. R. S. (2016). Seed morphometry and germination of Aechmea constantinii (Mez) L. B. Sm. (Bromeliaceae). Revista Caatinga, 29(1).

Rivers, M., Shaw, K., Beech, E., \& Jones, M. (2015). Conserving The World's Most Threatened Trees: A Global Survey of Ex-situ Collections. Surrey, UK: Botanic Gardens Conservation International.

Rusdy, M. (2017). A review on hardseedness and breaking dormancy in tropical forage legumes. Livestock Research for Rural Development, 29(12), 1-8.

Sangalli, A., Vieira, M. C., Scalon, S. P. Q., Zarate, N. A. H., Silva, C. B., \& Ribeiro, I. S. (2012). Fruit and seed morphometry and germination of "carobinha" (Jacaranda decurrens subsp. symmetrifoliolata) seeds after storage. Revista Brasileira Plantas Medica, 14(2), 267-275.

Schmidt, L. (2002). Guidelines for Handling Tropical and Sub-Tropical Forest Seeds. Jakarta: Cooperation of Directorate General of Land Rehabilitation and Social Forestry with Indonesian Forest Seed Project.
Solberg, S. Ø., Yndgaard, F., Andreasen, C., Bothmer, R. V., Loskutof, I. G., \& Asdal, A. (2020). Long-term storage and longevity of orthodox seeds: a systematic review. Frontiers in Plant Science, 11, article 1007.

Sraphet, S., Sukawutthiya, P., Srisawad, N., Smith, D. R., \& Triwitayakorn, K. (2021). Evaluation of the genetic diversity of Bauhinia winitii, an endemic plant of Thailand, using microsatellite markers. Philippine Journal of Science, 150(2), 557-569.

Sutopo, L. (2010). Seed Technology. Jakarta: PT Raja Grafindo Persada.

Tauro, T. P., Nezomba, H., Mtambanengwe, F., \& Mapfumo, P. (2009). Germination, field establishment patterns and nitrogen fixation of indigenous legumes on nutrient-depleted soils. Symbiosis, 48, 92-101.

Waiboonya, P., Elliott, S., \& Tiansawat, P. (2019). Seed storage behaviour of native forest tree species of northern Thailand. Environment Asia, 12(3), 104-111.

Wen, H. X., Wu, P. Y., \& Wang, R.Y. (2009). Different requirements for physical dormancy release in two populations of Sophora alopecuroides relation to burial depth. Ecological Research, 24, 1051-1056.

Zanzibar, M. (2017). Dormancy tipe and pretreatment of seed dormancy of Balsa (Ochroma bicolor Rowlee). Jurnal Perbenihan Tanaman Hutan, 5(1), 51-60.

Zhang, F. P., Zhang, J. J., Yan, N., Hu, H., \& Zhang, S. B. (2015). Variations in seed micromorphology of Paphiopedilum and Cypripedium (Cypripedioideae, Orchidaceae). Seed Science Research, 25, 395-401.

Zuhri, M., Latifah, D., Kurniawati, F., Noviady, I., \& Suhendri, Y. (2019). Seed exploration for seed banking purpose in Cibodas Botanical Garden. Biosaintifika, 11(1), 162-170. 